\title{
HIV prevalence among men who have sex with men in Iran: A systematic review and meta-analysis
}

\author{
Leila Ghalichi ${ }^{1}$, Morteza Naserbakht ${ }^{1}$, Mehrdad Eftekhar Ardebili ${ }^{1} * \mathbb{D}$, Leila Janani ${ }^{2,3}$, Omid Pournik ${ }^{4}$, Fatemeh Tavakoli ${ }^{5}$, \\ Ali Akbar Haghdoost ${ }^{6}$, Hamid Sharifi ${ }^{5}$
}

Received: 26 Sep 2020

Published: 23 Sep 2021

\section{Abstract}

Background: The need for informed policymaking highlights the importance of data on human immunodeficiency virus (HIV) prevalence on key populations. In this systematic review and meta-analysis, we aimed to provide an overview of HIV prevalence in men who have sex with men (MSM) in Iran.

Methods: We searched literature published between January 2008 and December 2019 to identify studies reporting the prevalence of HIV infection or acquired immunodeficiency syndrome (AIDS) in a population of adult Iranian men with history of sexual contact with other men. We employed Metaprop command in Stata to pool proportions from different studies.

Results: Among the 16 studies retrieved, 2 were performed on MSM population directly, 7 among people who inject drugs, 4 among prisoners, 2 among the homeless, and 1 among methamphetamine users. HIV prevalence was 7\% (95\% CI, 5\%-10\%) based on the meta-analysis, although noticeable heterogeneity existed because of target population, study year, and study location, which imposed limitations to provide a robust summary measure for the prevalence of HIV.

Conclusion: There is a potential risk of observing a high prevalence of HIV in MSM that could hamper the results of various preventive strategies and their achievements in other subpopulations.

Keywords: Human Immunodeficiency Virus, Acquired Immunodeficiency Syndrome, Sexual and Gender Minorities, Key Population

Conflicts of Interest: None declared

Funding: The research was supported by Iran University of Medical sciences (IR.IUMS.REC.1396.32658).

\section{*This work has been published under CC BY-NC-SA 1.0 license.}

Copyright $\odot$ Iran University of Medical Sciences

Cite this article as: Ghalichi L, Naserbakht M, Eftekhar Ardebili M, Janani L, Pournik O, Tavakoli F, Haghdoost AA, Sharifi H. HIV prevalence among men who have sex with men in Iran: A systematic review and meta-analysis. Med J Islam Repub Iran. 2021 (23 Sep);35:123. https://doi.org/10.47176/mjiri.35.123

\section{Introduction}

Although the global efforts have led to a remarkable decline in new human immunodeficiency virus (HIV) infections, the pace is considered slow compared to expectations. At present, half of HIV incidence occurs among key populations and their partners who are generally ignored in policymaking and prevention programs (1). There have been achievements in high-burden countries, yet the rate is

Corresponding author: Dr Mehrdad Eftekhar Ardebili, eftekharardebili.m@iums.ac.ir

1. Mental Health Research Center, Psychosocial Health Research Institute, Iran University of Medical Science, Tehran, Iran

2. Preventive Medicine and Public Health Research Center, Psychosocial Health Research Institute, Iran University of Medical Science, Tehran, Iran

3. Department of Biostatistics, School of Public Health, Iran University of Medical Sciences, Tehran, Iran

4. Preventive Medicine and Public Health Research Center, Psychosocial Health Research Institute, Community and Family Medicine Department, School of Medicine, Iran University of Medical Sciences, Tehran, Iran

5. HIV/STI Surveillance Research Center, and WHO Collaborating Center for HIV Surveillance, Institute for Futures Studies in Health, Kerman University of Medical Sciences, Kerman, Iran

6. Social Determinants in Health Research Center, Institute for Futures Studies in Health, Kerman University of Medical Sciences, Kerman, Iran

still increasing in key populations $(2,3)$. Men who have sex with men (MSM) are one of the key populations who have been experiencing high rates during the past decade, even in countries with successful HIV control in other subpopulations (4).

The term MSM is used to target sexual behaviors regardless of sexual orientation or gender identity. The term

$\uparrow$ What is "already known" in this topic:

Men who have sex with men (MSM) are one of the key populations who have been experiencing high rates of HIV infection during the past decades, even in countries with successful HIV control programs.

\section{$\rightarrow$ What this article adds:}

Despite the relatively low HIV prevalence in Iran, the higher rates in MSM population could impose a potential risk to national preventive strategies. 
includes homosexual and bisexual men as well as male sex workers, those in all-male settings, such as prisons, but not transgender people born male. MSM is a broader category than homosexual men and recognizes other subgroups that might be more hidden and difficult to identify. These difficulties result in limited information on these subpopulations, especially in communities where these sexual behaviors have social stigma or criminal charges (5). Even in communities with no legal limitations, cultural and social barriers may hinder information disclosure in epidemiologic studies (6), while detailed understanding of the epidemic trends and stages in every key population is essential in developing appropriate interventions (7).

Policymakers have targeted both behavioral and biomedical prevention strategies at different stages of the epidemics, but the success rate was not optimal because of cultural and social characteristics, limited access to HIV testing and care, legal issues, and different antiretroviral drug-resistance patterns, among other reasons $(8,9)$. In communities with low overall prevalence of HIV, or where the epidemic is limited to some subgroups, updated and reliable statistics is critical in planning interventions (7). Such data are not available in many countries or are only available in a limited and biased manner (10). On the other hand, many epidemiologic studies do not contain information on MSM-related behaviors, fearing that adding such questions may decrease data completeness and response rate and impose bias to the results, making direct assessments even more difficult (11).

Despite the relatively low overall HIV prevalence of $0.1 \%$ in the Middle-East, there has been $66 \%$ rise in HIVrelated deaths in the recent decade, which rings the bell for policymakers on preventive measures (12). Until recent years, the majority of the infections occurred in men; and shared needle was the main route of transmission, but this profile has been rapidly changing. Despite the decreased prevalence in people who inject drugs (PWID), a rise has been reported on the prevalence of infection among women; and sexual transmission is becoming a more dominant transmission route (13). These changes may require new policies to maintain the epidemics limited to the key populations.

The need for informed policymaking highlights the importance of data on HIV prevalence on key populations. MSM are among the key populations with limited studies directly targeting them. In this research, we aimed to provide an overview of HIV prevalence in MSM through data presented in studies where MSM-related behaviors are directly or indirectly presented.

\section{Methods}

This study was reported according to the PRISMA (Preferred Reporting Items for Systematic Reviews and Metaanalysis) guidelines (14), and was approved and supported by Iran University of Medical Sciences.

\section{Search Method}

To identify relevant studies, the literature was searched for Persian and non-Persian documents in international and national databases. Due to the limited literature on
MSM population in Iran, we needed to screen the literature with high sensitivity; thus, an inclusive search strategy was applied to access all possible documents. Moreover, we searched the gray literature and hand searched the reference lists of included articles and communicated with well-known researchers and research institutes as well as governmental health authorities.

The search process was performed in January 2020 on the literature published from January 2008 until December 2019. A comprehensive search was performed on databases with Persian documents; Islamic World Science Citation Center, Scientific Information Database, database of Iranian Research institute for information science and Technology, and Magiran. Also, a literature search was conducted in PubMed, Scopus, and Web of Science (WOS) without any language limits. The keywords used were "Human Immunodeficiency Virus" and "Iran," as well as similar terms such as "HIV" or "Persian" or "Iranian."

\section{Study Selection}

Eligible studies were those that clearly reported the prevalence of HIV infection or acquired immunodeficiency syndrome (AIDS) in a population of men with history of sexual contact with other men. Articles were included if they reported a sample or subsample of men who reported engaging in at least 1 event of any type of sex with another man through personal desire, or engaging in sex for money, drugs, etc. Studies on Iranian people living in other parts of the world, those that reported prevalence in females or in people younger than 15 years, and secondary studies were excluded. In addition, if key information (number of MSM tested and their HIV test results) were missing and could not be obtained by contacting the authors, the study would be excluded.

\section{Data Extraction}

After removing the duplicate articles, 2 authors (L.G. and O.P.) independently evaluated titles and abstracts of the extracted articles for eligibility. We included articles approved by at least 1 of the researchers for full-text evaluation. At this stage, any disagreement between the researchers was resolved in a discussion session with all the research team.

\section{Risk of Bias Assessment}

We evaluated risk of bias in selected studies using a tool modified by Hoy et al. This tool evaluates internal and external validity of the studies using a 10 -item rating. External validity was assessed by examining 4 items: nationally representativeness, sampling frame, random selection or census, and likelihood of nonresponse. Internal validity was determined based on 6 items: direct data collection, case definition, valid instrument, consistency of data collection method, duration of period prevalence, and appropriate numerator and denominator. Each item was assigned 0 or 1 , indicating low or high risk of bias, respectively. If judgement could not be made based on the information in the article, the item would be categorized as high risk (15). Studies that received more than 8 scores 
were considered as having a low risk of bias, while those with 6 to 8 scores were categorized as having a moderate bias. The rest would be labeled as high risk.

\section{Statistical Analysis}

Considering the different epidemiologic profiles of subpopulations in this study (PWID, prisoners, homeless, MSM, and methamphetamine users), the HIV prevalence presented separately in each subgroup. We employed forest plots, Cochran's Q statistic, and I2 statistic to evaluate heterogeneity among the primary studies.

Metaprop command in Stata Version 14 (StataCorp) was used to pool proportions from different studies. We tested publication bias using Egger regression asymmetry tests to determine the asymmetry of the funnel plots, with $\mathrm{p}<0.10$ as the evidence of bias.

\section{Results}

A total of 3403 articles were identified through literature search from different databases. After excluding duplicates and irrelevant articles, which were considerably numerous due to sensitive search strategy, 224 full-text articles were evaluated for relevance and quality. Finally, 9 articles (8 English; 1 Persian) were eligible for data extraction. Also, 7 studies were retrieved through hand search and communication with experts (Fig. 1).
Only 2 studies were performed on MSM population directly. Other studies were included, as they reported HIV prevalence among other subpopulations. Seven studies were among PWIDs, 4 among prisoners, 2 among the homeless, and 1 among methamphetamine. Studies were published 1 to 6 years after being performed. Number of MSM detected in each study ranged from 9 to 714 . HIV prevalence ranged from $0 \%$ to $44 \%$ (Table 1 ). The overall estimated prevalence was 7\% (95\% CI, 5\%-10\%). In PWID, the prevalence ranged from $1.6 \%$ to $44 \%$, with an average estimate of $15 \%$ (95\% CI, $8 \%-21 \%)$. HIV prevalence in MSM recruited from prisons ranged from $0 \%$ to $3.6 \%$, with a pooled estimate of $2 \%(95 \% \mathrm{CI}, 1 \%-4 \%)$. The prevalence of HIV in 2 studies on MSM directly was $14.8 \%$ and $2.3 \%$ (pooled estimate, $3 \%$; 95\% CI, $1 \%-4 \%$ ). In 2 studies with homeless target population, the prevalence ranged from $0 \%$ to $5.6 \%$, with an estimate of $1 \%$ to $19 \%$. There were no positive cases in the study on people who used methamphetamine.

The overall heterogeneity of the studies (I2) was $89.97 \%$, and heterogeneity was significant in the subpopulations (Fig. 2). When assessing bias and small study effects by the funnel plot observation and Begg's test, we observed an evidence of publication bias for prevalence, suggesting unpublished studies with different results (Fig. 3)

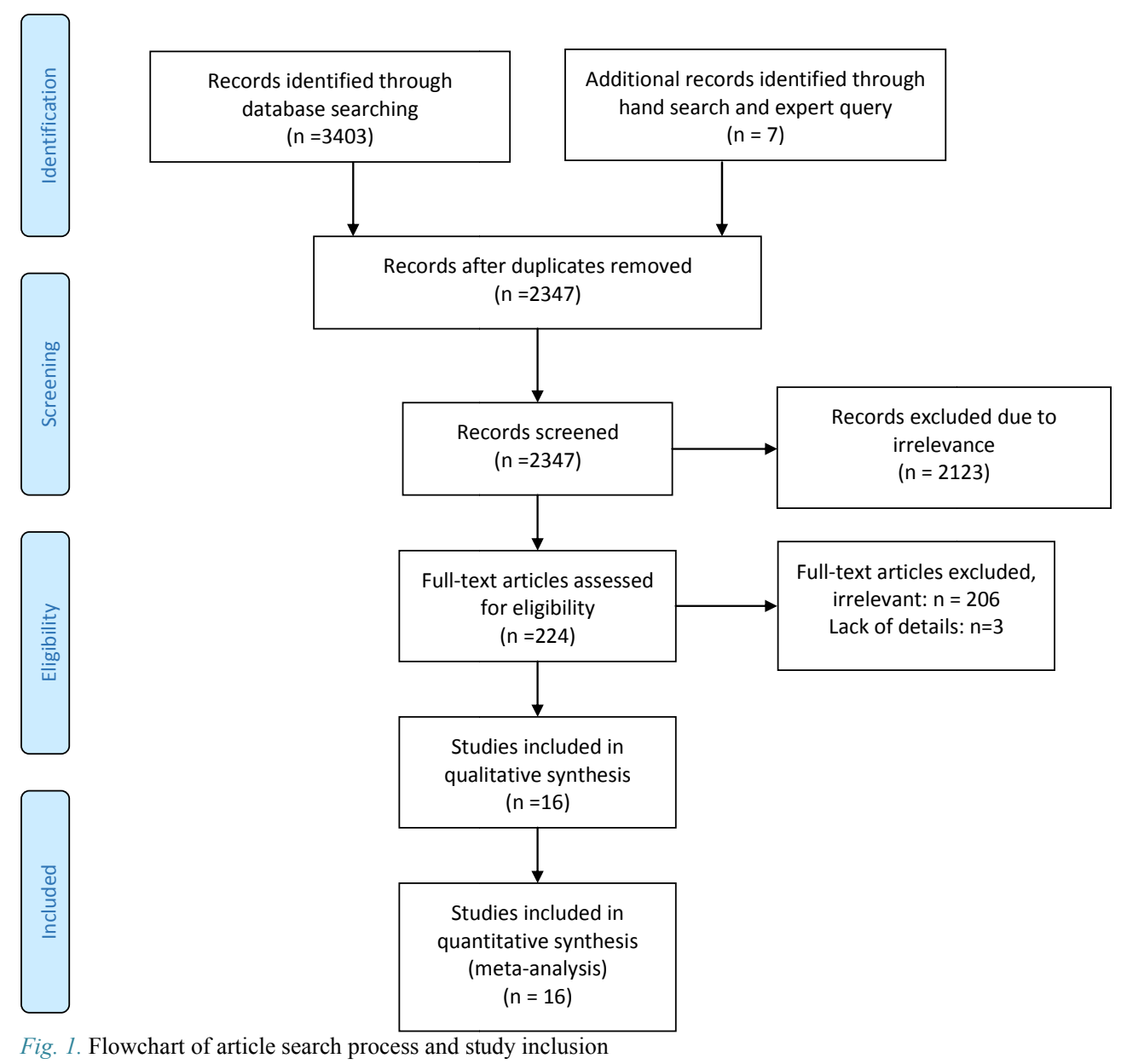




\begin{tabular}{|c|c|c|c|c|c|c|c|}
\hline $\begin{array}{l}\text { Recruitment } \\
\text { setting }\end{array}$ & Author & Population & Number & $\begin{array}{r}\text { Study } \\
\text { Year }\end{array}$ & $\begin{array}{c}\text { Publication } \\
\text { Year }\end{array}$ & $\begin{array}{c}\text { Prevalence } \\
(\%)\end{array}$ & $95 \% \mathrm{CI}$ \\
\hline PWID & Mirahmadizadeh et al (16) & $\begin{array}{l}\text { Country } \\
\text { level }\end{array}$ & 197 & 2008 & 2009 & 12.7 & 8.7 to 18.1 \\
\hline PWID & Kheirandish et al (17) & Tehran & 48 & 2006 & 2010 & 33.3 & $\begin{array}{l}21.6 \text { to } \\
47.5\end{array}$ \\
\hline PWID & Alavi et al (18) & Ahvaz & 30 & 2006 & 2012 & 40.0 & $\begin{array}{c}24.6 \text { to } \\
57.7\end{array}$ \\
\hline PWID & Moamen et al (19) & Kashan & 62 & 2010 & 2013 & 1.6 & 0.0 to 9.4 \\
\hline PWID & Ramezani et al (20) & Arak & 9 & 2012 & 2014 & 44.4 & $\begin{array}{c}18.8 \text { to } \\
73.4\end{array}$ \\
\hline PWID & $\begin{array}{l}\text { HIV/STI Surveillance Research } \\
\text { Center BSS } 2010 \text { (21) }\end{array}$ & $\begin{array}{l}\text { Country } \\
\text { level }\end{array}$ & 307 & 2010 & 2010 & 12.4 & 8.9 to 16.5 \\
\hline PWID & $\begin{array}{l}\text { HIV/STI Surveillance Research } \\
\text { Center BSS } 2014 \text { (22) }\end{array}$ & $\begin{array}{l}\text { Country } \\
\text { level }\end{array}$ & 333 & 2014 & 2014 & 6.9 & 4.4 to 10.1 \\
\hline Prisoners & $\begin{array}{l}\text { HIV/STI Surveillance Research } \\
\text { Center BSS } 2013 \text { (23) }\end{array}$ & $\begin{array}{l}\text { Country } \\
\text { level }\end{array}$ & 562 & 2013 & 2013 & 2.6 & 1.5 to 4.4 \\
\hline Prisoners & $\begin{array}{l}\text { HIV/STI Surveillance Research } \\
\text { Center BSS } 2017 \text { (24) }\end{array}$ & $\begin{array}{l}\text { Country } \\
\text { level }\end{array}$ & 714 & 2017 & 2017 & 1.4 & 0.7 to 2.5 \\
\hline Prisoners & Seyed Alinaghi et al (25) & Tehran & 280 & 2014 & 2017 & 3.6 & 1.9 to 6.5 \\
\hline Prisoners & Khademi et al (26) & Kermanshah & 95 & 2017 & 2019 & 0 & 0.0 to 4.6 \\
\hline MSM & Eftekhar et al (27) & Tehran & 101 & 2008 & 2008 & 14.8 & 7.7 to 26.5 \\
\hline MSM & Eftekhar et al (28) & Tehran & 435 & 2017 & 2017 & 2.3 & 1.2 to 4.2 \\
\hline Homeless & Amiri et al (29) & Tehran & 36 & 2012 & 2014 & 5.6 & 0.6 to 19.1 \\
\hline Homeless & $\begin{array}{c}\text { HIV/STI Surveillance Research } \\
\text { Center } 2017 \text { (30) }\end{array}$ & Kerman & 29 & 2017 & 2017 & 0 & 0.0 to 0.1 \\
\hline Methamphetamine users & Moradi et al (31) & $\begin{array}{l}\text { Country } \\
\text { level }\end{array}$ & 34 & 2017 & 2019 & 0 & 0.0 to 0.1 \\
\hline
\end{tabular}

${ }^{a}$ BSS, Bio-Behavioral Surveillance Survey; MSM, men who have sex with men; PWID, people who inject drugs.

\section{HIV Prevalence}

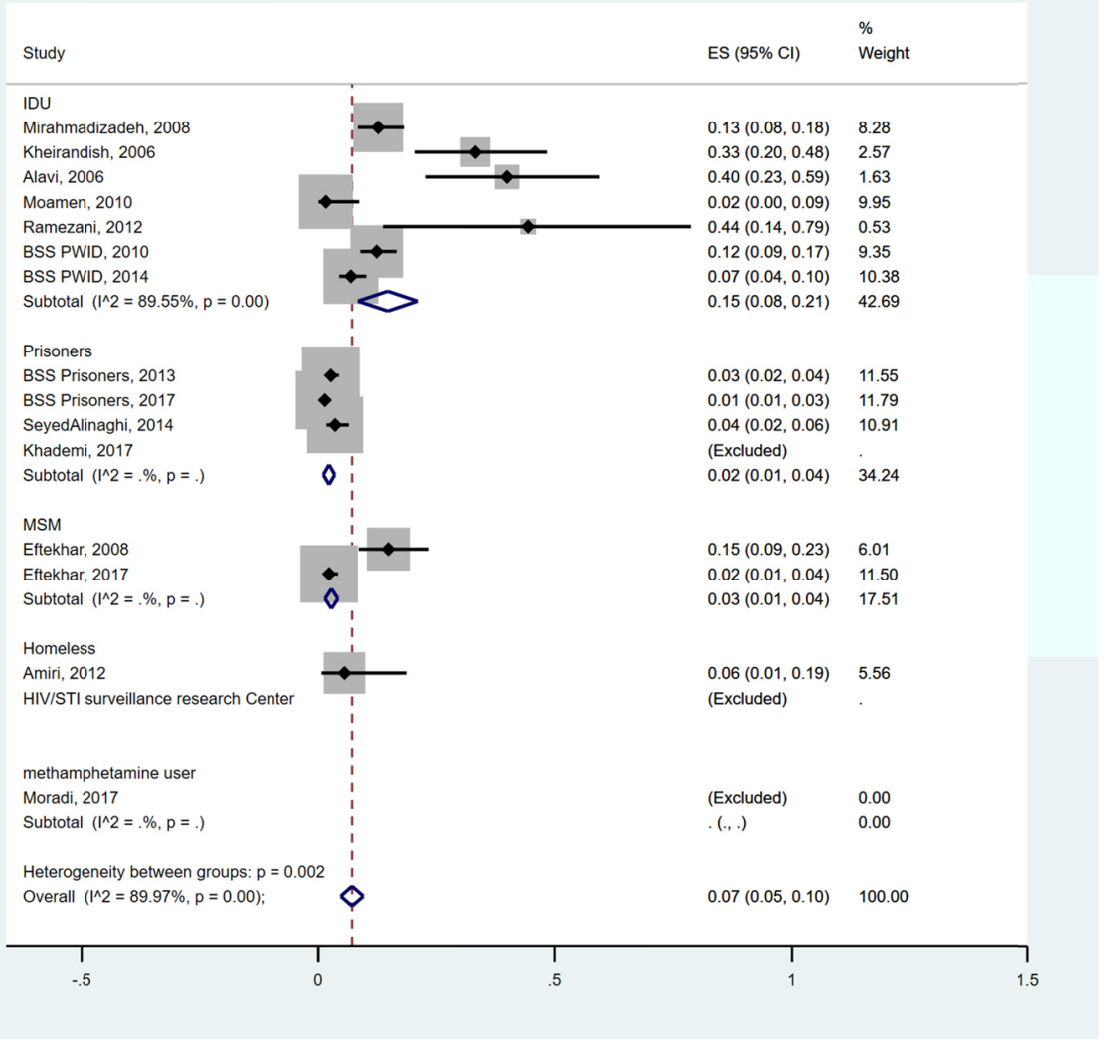

Fig. 2. Forest plot of HIV prevalence in population of men who have sex with men (MSM), based on the targe population of the original studies (Dates presented according to the data collection year, not publication year).

In quality assessment, the studies showed low to moderate risk of bias. Although the internal validity of the stud- ies was high, the external validity was relatively low, mostly because of different target population and repre- 


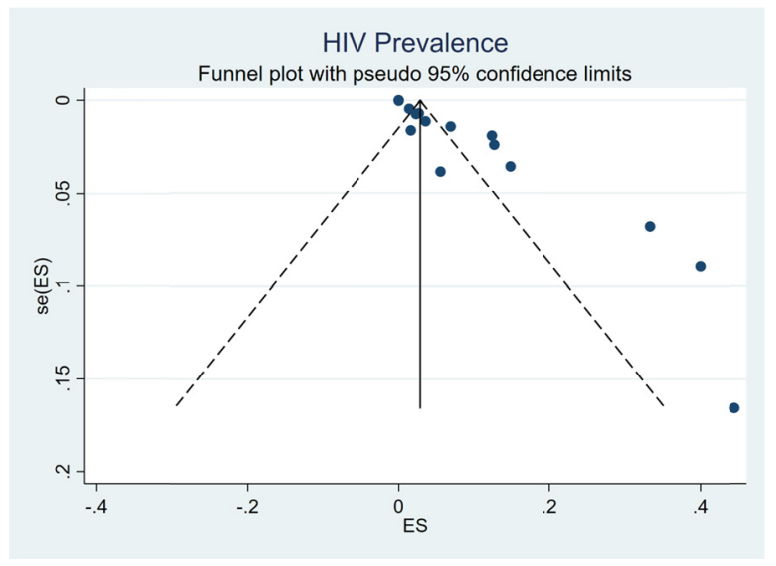

Fig. 3. Funnel plot for meta-analysis of the prevalence of HIV in men who have sex with men (MSM) in Iran

sentativeness (Table 2).

In Figure 4, the trend of HIV prevalence is shown according to the study year. Because of the wide and variable time span between study performance and study publication, the former was used for data presentation.

\section{Discussion}

In this review, we identified studies that evaluated HIV prevalence in MSM, either as their main target population, or as a subpopulation of other target groups, mainly PWID and prisoners in Iran. Because of the sparsity of studies with MSM as the main target population, most of the included data were extracted from studies that evaluated the HIV prevalence in other HIV key populations. We may indicate an overall $7 \%$ prevalence for HIV, but the heterogeneity between the studies imposes limitations to providing such summary measure. The characteristics of these studies resulted in the heterogeneity observed between the findings of the studies from different pathways. These heterogeneities impose limitations to providing a robust summary measure for the prevalence of HIV based on the 16 included studies.

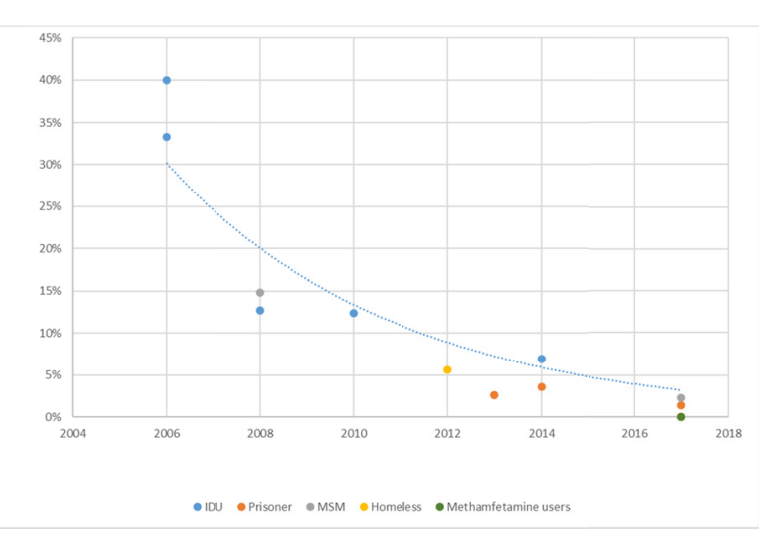

Fig. 4. HIV prevalence in men who have sex with men (MSM) population of the selected studies, according to the study year.

Study population is probably the most important source of heterogeneity. HIV prevalence is generally different in key populations, which is also reflected in our findings. Overall, HIV prevalence in MSM population was higher in PWID, compared to other subgroups, which is similar to the pattern in the country (32). This dual risk (sex and injection) could increase the prevalence of HIV among MSM with the injection behavior. In our study, the HIV prevalence was approximately $15 \%(8 \%-21 \%)$ in MSM population who also were in PWID subpopulation, and $2 \%(1 \%-4 \%)$ for those recruited from prisons. Previous reviews have reported HIV prevalence in prisoners of Iran, ranging between $0 \%$ and $24 \%$ (13). The study on the homeless population in Tehran yielded a $6 \%$ prevalence of HIV in homeless MSM, similar to a study from 2009 that reported a $4.6 \%$ in the homeless from the same city (33). In the only study on people using methamphetamine as the emerging high-risk population, no HIV positive cases were detected (31).

Another observation in this study was the decreasing trend of HIV prevalence in the study period that can be considered as another source of heterogeneity. This trend

Table 2. Quality Assessment* of Included Studies ${ }^{\mathrm{a}}$

\begin{tabular}{|c|c|c|c|c|}
\hline Reference & $\begin{array}{c}\text { External validity } \\
(0-4)\end{array}$ & $\begin{array}{c}\text { Internal Validity } \\
(0-6) \\
\end{array}$ & $\begin{array}{c}\text { Total Score } \\
(0-10)\end{array}$ & Risk of Bias \\
\hline Mirahmadizadeh et al (16) & 3 & 6 & 9 & Low \\
\hline Kheirandish et al (17) & 1 & 6 & 7 & Moderate \\
\hline Alavi et al (18) & 1 & 6 & 7 & Moderate \\
\hline Moamen et al (19) & 0 & 6 & 6 & Moderate \\
\hline Ramezani et al (20) & 0 & 6 & 6 & Moderate \\
\hline HIV/STI Surveillance Research Center 2010 (21) & 2 & 6 & 8 & Moderate \\
\hline HIV/STI Surveillance Research Center BSS 2014 (22) & 2 & 6 & 8 & Moderate \\
\hline HIV/STI Surveillance Research Center BSS 2013 (23) & 3 & 6 & 9 & Low \\
\hline HIV/STI Surveillance Research Center BSS 2017 (24) & 3 & 6 & 9 & Low \\
\hline Seyed Alinaghi et al (25) & 1 & 5 & 6 & Moderate \\
\hline Khademi et al (26) & 0 & 6 & 6 & Moderate \\
\hline Eftekhar et al (27) & 1 & 6 & 7 & Moderate \\
\hline Eftekhar et al (28) & 1 & 6 & 7 & Moderate \\
\hline Amiri et al (29) & 0 & 6 & 6 & Moderate \\
\hline HIV/STI Surveillance Research Center 2017 (30) & 1 & 5 & 6 & Moderate \\
\hline Moradi et al (31) & 1 & 6 & 7 & Moderate \\
\hline
\end{tabular}

${ }^{a}$ BSS, Bio-Behavioral Surveillance Survey

* The quality assessment tool from Hoy et al. (15) 
is more pronounced in studies performed with similar methodologies, such as 2 studies on MSM in Tehran (14.8\%-2.3\%); BSS for PWID (12.4\%-6.9\%), and BSS for prisoners $(2.6 \%-1.4 \%)$. In a systematic review, Musavi et al showed a constant decrease in HIV prevalence in Iranian blood donors who can be considered as a proxy of the general population (34). In another systematic review on HIV prevalence among PWID, a nonsignificant drop was observed from $19 \%$ to $8.8 \%$ between 2005 and 2010 . In Tehran after 2007, the prevalence decreased from $18.5 \%$ to $12.3 \%$ (35). Studies performed in different groups of HIV key populations in Iran also suggest that the increasing trend of HIV in 2000s has been replaced with a stabilized pattern in the recent decade (36). Evidence from different studies suggest that the decline in HIV prevalence among prisoners occurred more quickly, perhaps due to multiple interventions, such as voluntary counseling and testing, triangular clinics, methadone maintenance therapy, condom distribution, and conjugal visit rooms in prisons (37). Some researchers suggest that the decline in all subgroups of HIV key populations is a reflection of decrease in HIV prevalence in PWID (38).

We believe that the evidence provided by the studies on MSM is not enough to conclude about the trend of HIV in MSM, and a concrete interpretation of their result is misleading. Although some of the studies listed above had similar methodologies, existing differences may have noticeable impact on the result. For instance, although both MSM studies in Tehran used RDS sampling for subject recruitment, the initial seeds in Tehran MSM study (2007) were PWID-MSM that led PWID-MSM to be a considerable portion of the total study participants, while the initial seeds in 2017 study were not PWID. It should be highlighted that the main HIV transmission routes in Iran that used to be shared injection, is eventually being replaced with unsafe sexual practices (13). Moreover, the HIV trend is toward disproportionate concentrated epidemic in MSM in comparison to other key populations both in the Middle East and in other parts of the world (39-41).

Another source of heterogeneity is the geographic distribution of the studies. The included studies consisted of 6 country level studies, 5 studies from Tehran, and only 5 studies from other provinces. Other studies have highlighted the differences in the burden of HIV in Iranian provinces, with higher burden for Kermanshah, Tehran, Fars, Hormozgan, and Lorestan (42). Lack of data from many of these provinces could undermine the programs based on national estimates and overall trends of the country.

It should be reminded that in Middle East, many MSM also have sex with women, which can increase the chance of HIV transmission from MSM to the general population (43). Considering the change in HIV transmission pattern in Iran, from shared injection to unsafe sex (13), the need for extensive preventive programs for reducing high-risk behaviors in the population is highlighted (37). Consequently, as with other key populations (38), despite the observed decrease HIV prevalence, appropriate preventive measures are of critical importance for the community health.
Although Iran is among the few countries in the region to have established mechanisms for HIV surveillance (eg, monitoring pregnant women, biobehavioral surveys of key populations), MSM and transgenders have generally been overlooked, resulting in the lack of valid data for planning necessary interventions (44).

The most notable finding of this review might be the shortage of HIV research among MSM population, an important key population in HIV prevention and control. The shortage may be the result of the legal condition in Iran and their stigmatization due to cultural factors, making MSM more hidden and inaccessible as well as a sense of avoidance to the subject of MSM-related behaviors on part of the researchers. From another view, the studies in this review have a very important and inviting lesson for the researchers in the field of HIV and high-risk behaviors. The lesson is that conducting researches among MSM in Iran is feasible. Despite the higher concerns of MSM on privacy and confidentiality, especially when biological testing is undertaken, these studies show that researchers' presumptions that MSM do not cooperate in researches, fearing identification or discrimination might not be true. Providing a safe and secure environment for interview and testing, adhering to ethical considerations and confidentiality increase their cooperation.

We acknowledge that in our context, conducting research and providing services to MSM can be very challenging; however, these challenges are not unique to Iran and are structurally similar to those faced in other countries, both within and outside the Middle East. Successful policymaking and program implementation require unbiased evidence and accurate statistics about the MSM population, including the subpopulations, network characteristics, individuals' behaviors, and the prevalence of various sexually transmitted diseases. Moreover, based on the feasibility of the observational studies in this population, we may infer those interventions might also be feasible. Similar subject recruitment or chain referral methods of some of the studies could also be used to access MSM for delivering services, disseminating information, and referrals to prevention, care, and harm reduction programs.

In this study, we tried to provide some insight on a very hidden and overlooked population in Iran. Meanwhile, our findings should be considered in the context of their limitations. The sparsity of studies directly evaluating the prevalence in MSM and limited geographical distribution of these studies are the main limitations of this study. Some studies had small sample sizes that might provide unstable estimates, although sensitivity analysis did not reveal remarkable differences based on these studies. Most of the included studies applied a convenience sampling method that reduces generalizability of the findings. Meanwhile, we believe to have some degrees of publication bias because of social norms and ethicolegal considerations. Most of the included studies had a moderate level of bias, mainly because of weakness in external validity. Overall, the population included in this study are not considered representative of the MSM population and all estimates should be considered with regard to this limitation. 


\section{Conclusion}

MSM are a population of high importance in HIV prevention and control programs worldwide. Evidence from countries with successful HIV control programs show that despite relative success in other subpopulations, MSM might continue to experience high rates of infection. Despite the relatively low HIV prevalence in Iran, the higher risks in MSM population could impose a potential risk by transmitting the disease out of their community and hamper the results of various preventive strategies and their achievements in other subpopulations. As with other countries in the world, Iran needs an integrated program to target MSM, other key populations, and the general population to maintain the risk limited and keep the epidemics concentrated.

\section{Acknowledgement}

We appreciate all researchers who provided complementary data needed from their studies.

\section{Conflict of Interests}

The authors declare that they have no competing interests.

\section{References}

1.UNAIDS. Miles to go-closing gaps, breaking barriers, righting injustices. UNAIDS Geneva; 2018.

2. Beyrer C, Sullivan P, Sanchez J, Baral SD, Collins C, Wirtz AL, et al. The increase in global HIV epidemics in MSM. Aids. 2013;27(17):2665-78.

3. Campbell CK, Lippman SA, Moss N, Lightfoot M. Strategies to Increase HIV Testing Among MSM: A Synthesis of the Literature. AIDS Behav. 2018;22(8):2387-412.

4.Hessou PHS, Glele-Ahanhanzo Y, Adekpedjou R, Ahouada C, Johnson RC, Boko M, et al. Comparison of the prevalence rates of HIV infection between men who have sex with men (MSM) and men in the general population in sub-Saharan Africa: a systematic review and meta-analysis. BMC Public Health. 2019;19(1):1634.

5. Beyrer C, Baral SD, Van Griensven F, Goodreau SM, Chariyalertsak S, Wirtz AL, et al. Global epidemiology of HIV infection in men who have sex with men. Lancet. 2012;380(9839):367-77.

6. Lippman SA, Lane T, Rabede O, Gilmore H, Chen YH, Mlotshwa $\mathrm{N}$, et al. High Acceptability and Increased HIV-Testing Frequency After Introduction of HIV Self-Testing and Network Distribution Among South African MSM. J Acquir Immune Defic Syndr. 2018;77(3):279-87.

7. Brown T, Peerapatanapokin W. Evolving HIV epidemics: the urgent need to refocus on populations with risk. Curr Opin HIV AIDS. 2019;14(5):337-53.

8. Pham QD, Wilson DP, Law MG, Kelleher AD, Zhang L. Global burden of transmitted HIV drug resistance and HIV-exposure categories: a systematic review and meta-analysis. Aids. 2014;28(18):2751-62.

9. Pantalone DW, Nelson KM, Batchelder AW, Chiu C, Gunn HA, Horvath KJ. A Systematic Review and Meta-Analysis of Combination Behavioral Interventions Co-Targeting Psychosocial Syndemics and HIV-Related Health Behaviors for Sexual Minority Men. J Sex Res. 2020:1-28.

10. Weir SS, Baral SD, Edwards JK, Zadrozny S, Hargreaves J, Zhao $\mathrm{J}$, et al. Opportunities for enhanced strategic use of surveys, medical records, and program data for HIV surveillance of key populations: scoping review. JMIR Public Health Surveill. 2018;4(2):e28.

11. Harling G, Gumede D, Mutevedzi T, McGrath N, Seeley J, Pillay $\mathrm{D}$, et al. The impact of self-interviews on response patterns for sensitive topics: a randomized trial of electronic delivery methods for a sexual behaviour questionnaire in rural South Africa. BMC Med Res Methodol. 2017;17(1):125.
12. Gökengin D, Doroudi F, Tohme J, Collins B, Madani N HIV/AIDS: trends in the Middle East and North Africa region. Int J Infect Dis. 2016;44:66-73.

13. Akbari M, Akbari M, Naghibzadeh-Tahami A, Joulaei $H$, Nasiriyan M, Hesampour M, et al. Prevalence of HIV/AIDS among Iranian Prisoners: A Review Article. Addict Health. 2016;8(3):195206.

14. Moher D, Liberati A, Tetzlaff J, Altman DG, Group P. Preferred reporting items for systematic reviews and meta-analyses: the PRISMA statement. PLoS Med. 2.009;6(7):e1000097.

15. Hoy D, Brooks P, Woolf A, Blyth F, March L, Bain C, et al. Assessing risk of bias in prevalence studies: modification of an existing tool and evidence of interrater agreement. J Clin Epidemiol. 2012;65(9):934-9.

16. Mirahmadizadeh AR, Majdzadeh R, Mohammad K, Forouzanfar M. Prevalence of HIV and hepatitis $\mathrm{C}$ virus infections and related behavioral determinants among injecting drug users of drop-in centers in Iran Iran Red Crescent Med J. 2009; 11(3):325-329.

17. Kheirandish P, Seyedalinaghi S, Hosseini M, Jahani M, Shirzad $\mathrm{H}$, Foroughi $\mathrm{M}$, et al. Prevalence and correlates of HIV infection among male injection drug users in detention in Tehran, Iran. J Acquir Immune Defic Syndr. 2010;53(2):273-5.

18. Alavi SM, Nadimi M, Shokri S, Zamani G. Seroepidemiology of Human Immunodeficiency Virus in Illicit Substance Users in Ahvaz, Iran: 2005-2006. Jundishapur J Microbiol. 2012;5(3):474-8.

19. Moamen Heravi M, Afzalli H, Razaghi R, Vakili Z. Seroprevalence of HIV and Hepattitis B Virus Infection and Related Risk Factors Among Injection Drug Users in Kashan. Alborz Univ Med J. 2013;2(3):156-62.

20. Ramezani A, Amirmoezi R, Volk JE, Aghakhani A, Zarinfar N, McFarland W, et al. HCV, HBV, and HIV seroprevalence, coinfections, and related behaviors among male injection drug users in Arak, Iran. AIDS Care. 2014;26(9):1122-6.

21. HIV/STI Surveillance Research Center and WHO Collaborating Center for HIV Surveillance, Sciences KUoM. National HIV BioBehavioural Surveillance Survey (BBSS) of Injecting Drug Users (IDUs) in Iran 2010 [Available from: http://hivhub.ir/nationalprojects/.

22. HIV/STI Surveillance Research Center and WHO Collaborating Center for HIV Surveillance, Sciences KUoM. Third National BioBehavioural Surveillance Survey in PWIDs in Iran 2014 [Available from: http://hivhub.ir/national-projects/.

23. HIV/STI Surveillance Research Center and WHO Collaborating Center for HIV Surveillance, Sciences KUoM. Third National BioBehavioural Surveillance Survey in Prisoners in Iran 2013 [Available from: http://hivhub.ir/mational-projects/.

24. HIV/STI Surveillance Research Center and WHO Collaborating Center for HIV Surveillance, Siciences KUoM. Fourth National HIV Bio- Behavioural Surveillanice Survey (BBSS) in Prisoners in Iran 2017 [Available from: http://hivhub.ir/national-projects/.

25. SeyedAlinaghi SA, Farhoudi B, Mohraz M, Pahlaviani FG, Hosseini M, Farnia M, et al. Prevalence and correlates of HIV infection among male prisoners in Tehran, Iran. Arch Iran Med. 2017;20(6).

26. Khademi N, Shakiba E, Khodadost M, Khoramdad M. Seroprevalence and related risk behaviors of hepatitis C, hepatitis B and HIV infections among Male prisoners in Kermanshah, Iran. Arch Iran Med. 2019;22(10):588-91.

27. Eftekhar M, Feizzadeh A, Moshtagh Bidokhti N, Setayesh H, Vasigh A, Azadmanesh K. High risk behavior and HIV/AIDS prevalence among men having sex with men: the first report from Iran. Unpublished report. 2008.

28. Eftekhar M, Gouya M, Kazerooni P, Ranjbar H, Taban M, Akbarpour S. The evaluation of HIV, STD, behavioural patterns and highrisk behaviours in MSM in Tehran and Karaj [Report in Persian]. 2017.

29. Amiri FB, Gouya MM, Saifi M, Rohani M, Tabarsi P, Sedaghat A, et al. Vulnerability of homeless people in Tehran, Iran, to HIV, tuberculosis and viral hepatitis. PLoS One. 2014;9(6).

30. HIV/STI Surveillance Research Center and WHO Collaborating Center for HIV Surveillance KS. Health Status of 18-to-29-years Homeless Youth in Kerman. 2017.

31. Moradi G, Hajarizadeh B, Rahmani K, Mohamadi-Bolbanabad A, Darvishi S, Zareie B, et al. Drug use and risk behaviour profile, and the prevalence of HIV, hepatitis C and hepatitis B among people 
with methamphetamine use in Iran. Int J Drug Policy. 2019;73:12934.

32. Mirahmadizadeh A, Majdzadeh R, Mohammad K. Costeffectiveness analysis of HIV/AIDS prevention among intravenous drug users in Iran's Drop-in Centers. J Health Sci Surveill Syst. 2018;6(2):52-7.

33. Vahdani P, Hosseini-Moghaddam SM, Family A, MohebDezfouli R. Prevalence of HBV, HCV, HIV, and Syphilis among Homeless Subjects Older than Fifteen Years in Tehran. Arch Iran Med. 2009;12(5):483-7.

34. Musavi H, Rahimi H, Kooti W, Dorostkar R, Azami M, Sharghi $\mathrm{M}$, et al. Prevalence of human immunodeficiency virus in Iranian blood donors: A systematic review and meta-analysis. Arch Iran Med. 2018;21(6):260-7.

35. Rahimi J, Gholami J, Amin-Esmaeili M, Fotouhi A, Rafiemanesh $\mathrm{H}$, Shadloo B, et al. HIV prevalence among people who inject drugs (PWID) and related factors in Iran: a systematic review, metaanalysis and trend analysis. Addiction. 2020;115(4):605-22.

36. Sharifi H, Mirzazadeh A, Shokoohi M, Karamouzian M, Khajehkazemi R, Navadeh S, et al. Estimation of HIV incidence and its trend in three key populations in Iran. PloS One. 2018;13(11).

37. Bagheri Lankarani K, Zarei N, Joulaei H. Strategies to reduce HIV transmission amongst prisoners; lessons learned from Iran. J Res Health Sci. 2017;17(3).

38. Mirzazadeh A, Shokoohi M, Karamouzian M, Ashki H, Khajehkazemi R, Salari A, et al. Declining trends in HIV and other sexually transmitted infections among female sex workers in Iran could be attributable to reduced drug injection: a cross-sectional study. Sex Transm Infect. 2020;96(1):68-75.

39. Fan S, Lu H, Ma X, Sun Y, He X, Li C, et al. Behavioral and serologic survey of men who have sex with men in Beijing, China: implication for HIV intervention. AIDS Patient Care STDS. 2012;26(3):148-55.

40. Mumtaz G, Hilmi N, McFarland W, Kaplan RL, Akala FA, Semini I, et al. Are HIV epidemics among men who have sex with men emerging in the Middle East and North Africa?: a systematic review and data synthesis. PLoS Med. 2011;8(8):e1000444.

41. Kerr LR, Mota RS, Kendall C, Pinho AdA, Mello MB, Guimaraes $\mathrm{MD}$, et al. HIV among MSM in a large middle-income country. Aids. 2013;27(3):427-35

42. Moradi G, Piroozi B, Alinia C, Akbarpour S, Gouya MM, Saadi $\mathrm{S}$, et al. Incidence, mortality, and burden of HIV/AIDS and its geographical distribution in Iran during 2008-2016. Iran J Public Health. 2019;48(Supple 1):1-9.

43. Haghdoost AA, Mostafavi E, Mirzazadeh A, Navadeh S, Feizzadeh A, Fahimfar N, et al. Modelling of HIV/AIDS in Iran up to 2014. J AIDS HIV Res. 2011;3(12):231-9.

44. Haghdoost AA, Karamouzian M, Nasirian M. Recent Advances of the HIV Surveillance System in Iran; Current Situation and Ways Forward. Sex Transm Infect. 2013. https://sti.bmj.com/content/ recent-advances-hiv-surveillance-system-iran-current-situation-andways-forward. 